\title{
BUYING INTO 'GREEN' IDENTITY: REPRESENTATION OF SUSTAINABLE CONSUMPTION IN LATVIAN LIFESTYLE MAGAZINES (2013 - 2018)
}

\author{
Marita Zitmane ${ }^{1}$, Dr.sc.comm. \\ ${ }^{1}$ Department of Communication Science, University of Latvia
}

\begin{abstract}
There is a growing consensus that, altering consumption patterns is one of society's greatest challenges in the quest for sustainable development. Green consumption must be understood in terms of a process that has led to individuals feeling both responsible for and empowered in dealing with risks to both themselves and to the wider environment. Media representations can be considered to be a lifestyle and identity instruction for the consumer. Thus it is important to study what kind of representations there are in media in regards to green consumption. In order to do so, the most popular lifestyle magazine in Latvia Ieva was analysed in time period from 2013 till 2018. Results of analysis show that there are very few publications in magazine which are dedicated to issues of sustainability and green lifestyle. Lot of products are represented as natural but without explanation why and how product is natural. Identity of green consumer represented in magazine is one of consumer whose consumption acts are primarily based on micro motivations and focus on an individual's right to better environmental circumstances.
\end{abstract}

Key words: sustainability, consumption, consumer, identity, media.

JEL code: $Z 1$.

\section{Introduction}

The rise of contemporary environmentalism in Western Europe can be traced to the 1960s and early 1970s, as concern grew about the impact of both consumption and production patterns on the environment (Cohen, 2001). As awareness of the environmental effects of advanced capitalism grows, we witness the progression of 'sustainable' consumption movements. Green consumption is now perceived as an element of environmental reform in many western societies and indeed within supra-national blocs such as the European Union (EU) (Buttel,2003). "Sustainable” here refers to a level and pattern of consumption, which meets the needs of the present without compromising the ability of future generations to meet their own needs (World Commission on Environment Development, 1987).

The notion of sustainability and the concept of sustainable consumption have recently emerged as in the academic debates that consider the environmental impacts of consumption as well.

Giddens (1991) argues that lifestyle choices, within the settings of local-global interrelations, raise moral issues that cannot simply be pushed to one side. Consumers influence the environmental landscape with their behaviour through purchasing, use practices, and recycling (Ruppert-Stroescu, LeHew, Connell, Armstrong, 2015). Green consumption must be understood in terms of a process that has led to individuals feeling both responsible for and empowered in dealing with risks to both themselves and to the wider environment (Prothero, Connolly, 2008). In this context one can distinguish a certain type of consumer; a green consumer is someone who is very concerned about the environment and therefore, only purchases products that are environmentally friendly or ecofriendly with little or No packaging, products made from natural ingredients and products that are made without causing pollution or detriment to the environmental quality (like emission hazards) (Sarkar, 2012).

This translates in particular consumer choices, which can be successfully used in marketing and profit creating as well. For example, some studies suggest that consumers are willing to pay more

${ }^{1}$ Marita Zitmane. Tel.: +371 (29783585). E-mail address: marita.zitmane@lu.Iv 
for some green goods at premium prices (Ottman, 1993). Green marketing is wildly used strategy to sell consumer goods for people who identifies themselves as green consumers.

When discussing the problem of unsustainable consumption, there is a perhaps natural tendency to focus on individual consumers' decision making and behaviour. However, the attitudes, preferences, and choices of individual consumers may be more consistent with the cultural values and norms of society. The sustainability of final consumption depends on individual consumer choices, but individual choices are severely constrained by a range of macro and structural factors media being one of those factors (Prothero, McDonagh, Dobscha, 2010). In order to have a better understanding of consumer choices, media representation of consumption must be analysed. Consumerism undoubtedly is promoted and strengthened by media discourses. The media and marketing activities often tell people what is the best and most appropriate how to celebrate.

In discussing perspectives of sustainable consumption in Latvian press, the author will look at following research questions: 1 ) What is meant by sustainability, green and natural and eco-friendly in publications? 2) What reasons if any are provided for positioning consumer goods and lifestyles as eco-friendly, natural and sustainable? 3) What is identity of green consumer?

\section{Research results and discussion}

In order to limit the research field, weekly magazine Ieva has been chosen for analysis. According to research and consulting company Kantar TNS magazine, Ieva was the most read publication in Latvia in 2018 (Kantar TNS). Ieva is weekly lifestyle magazine, which has been the most popular printed press publication in Latvia for a long time, even ahead of daily newspapers in terms of audience size. Thus analysis of this magazine will provide information on how green consumption/ sustainable consumption is communicated in media.

To cover the entire analysis period, magazine editions for two months from each year were analysed using method of content analysis. From year 2013, magazine editions of January and February were analysed; from year 2014; magazine editions of March and April were analysed; from year 2015, magazine editions of May and June were analysed; from year 2016, magazine editions of July and August were analysed; from year 2017, magazine editions of September and October were analysed; from year 2018, magazine editions of November and December were analysed. In total, 54 copies of magazine were analysed. This selection also covers the full cycle of the year and its different seasons and celebrations. This aspect is important due to the changes in consumption which is affected by seasons.

Discourse of sustainable or green consumption in magazine Ieva is manifested in several thematic blocks. Those blocks are 'overview of various consumer goods', articles or columns about sustainability. In this article I will examine the representation of green products and green consumer choices in aforementioned thematic blocks.

\section{Overview of various consumer goods}

Overview of various consumer goods in weekly magazine Ieva can be found in columns Ieva chooses, We like it, Ieva's wellness, Style, Beauty. The purpose of those columns is to introduce various consumer goods to the readers. It is important to stress that columns chosen for analysis aren't promotional materials. For purpose of this study No promotional materials were analysed. The products suggested in these columns are recommended by journalists of magazine, thus they are considered to be trustworthy by the magazines' audience. The goal of analysing aforementioned 
articles was to determine how and if any sustainable and eco-friendly products are communicated to the audience.

In the analysed materials No special focus is placed on sustainable consumer products. If product happens to be eco-friendly it is mentioned, but it doesn't serve as persuasion point. Magazine readers are not encouraged to choose particular product over other products because it is natural or green. Organic, natural or green qualities of the product are not emphasized or explained. If marketing description of the product contains such terms as natural or green or environment friendly, those terms are repeated in product description. However No further information is provided on why this product can be considered as eco, natural or green. Eco-cosmetic certificate Ecocert is mentioned in texts very randomly. Even if product is pictured with visible logo of the certificate on its packing it isn't mentioned in the article describing the product. One can assume that this information is not considered to be important or to be selling point for consumers.

Terminology used describing products is very limited. Term 'natural' is used in almost all cases, describing various products, various ingredients and various product characteristics, see Table 1.

Table 1

Use of term 'natural'

\begin{tabular}{|l|l|l|}
\hline \multicolumn{1}{|c|}{ products } & \multicolumn{1}{c|}{ ingredients } & \multicolumn{1}{|c|}{ characteristics } \\
\hline Natural serum & Natural ingredients & \\
Natural live water & Natural castor of zinc acid & \\
Natural cream & Natural colloidal silver & Natural consistency \\
Natural toning bb cream & $92 \%$ of the ingredients are & Natural remedy \\
Natural cosmetics & natural & Natural flavour \\
Natural, aromatic oil & Natural AHA & Natural ingredients \\
Natural sisal glove & $90 \%$ natural ingredients & Natural fixation \\
Natural honey of various flowers & Natural oil & Natural recipe \\
Natural unrefined salt without & Natural oils & \\
additives & Natural active ingredients & \\
Natural, innovative spray for hair & Natural plant dyes & \\
Natural, Ecocert colour &
\end{tabular}

There is No explanation given why and how product or ingredient or product characteristic can be considered as natural. It is quite hard to grasp the meaning of 'natural', what is meant with describing product as natural. In the most cases 'natural' is used as opposition of artificial and manmade. In my analysis I found No cases when term 'natural' is used as synonym to sustainable.

Other term used sporadically is 'friendly to your skin and nature' - phrase used quite often but without any further explanation, why this product is friendly to environment, what it means to be environment friendly.

The problem is rooted in marketing, which operates with superficial terms, and journalists are relaying on information provided by marketing not doing in-depth research. Thus audience is served with vague information, which is not sufficient to make informed decision about sustainable consumption.

\section{Topic of sustainability}

In analysed material, there were several series of articles which tackles the topic of green lifestyle. In 2014, magazine introduced new column: „Discovering Green Lifestyle. Ecological and healthy - to feel, eat and live better". In 2016 column "I commit to green" was introduced. It is worth to have in depth look into these articles, since those are the only cases in analysed period, which are explicitly dedicated to green lifestyle including green consumer choices. 
Column "Discovering Green Lifestyle. Ecological and healthy - to feel, eat and live better" is overview of various products, consumer goods which could make consumer to feel, eat and live better. Each column features 9 various products starting form wellness and beauty to food and house cleaning products.

Products featured in column form $12^{\text {th }}$ of March have No eco or other labels, which would support the claim that product is ecological (Ieva, 12.03.2014). The biggest part of products featured in the column in their description has No evidence on why this product can be considered eco or green. Back heater, pumpkin seed butter, mustard powder, mix of spices, dietary supplement, oyster mushroom growing set and avocado are products with No supporting information about the products greenness. The only product with evidence provided is face cream. Description of it claims that it is made by producer of eco-cosmetics, evidence supporting this claim is not given, however one can notice bio and vegan labels on the image of the product.

In other articles from this column situation is different with several product featuring eco labels and other labels of sustainability. Column from $19^{\text {th }}$ of March describes 9 products; only two of products feature vegan labels - curry and mango tofu and shampoo (Ieva, 19.03.2014). In this case proof that product is eco can be found looking at the product; vegan labels are visible on packaging. Other products form this column are Jerusalem artichoke powder, stevia sweetener, lilac wine, dust remover, bread, spinach and flint. Again magazine fails to provide any scientific or liable reason why products are considered to be eco-friendly. Quite the opposite, it uses pseudo-science as evidence in case of flint: "various stones, including flint, help to clean and structure the water" (Ieva, 19.03.2014).

In next column, one product is featuring Ecocert certification label (body lotion), other Organic farmers and growers labels (crystal salt). Again information about certificates are seen on the image of the product, but not mentioned in description of the products. Other products which are presented as green but without any solid evidence are muesli bar, massager, air purifier, hemp protein, dietary supplement, humus and brush. In the last column the author analysed three products have bio certificate (coconut oil, quinoa, vegetarian broth cubes) and one (latex household glows) has FSC certificate (forest management certification). Other products with No given evidence on their greenness are halva, blanket, vitamins, sprouting barley and backpacks (Ieva, 14.04.2014).

Column doesn't live up to its promise - "Discovering Green Lifestyle. Ecological and healthy - to feel, eat and live better". This column should not be considered as trustworthy source of information to model one's green consumer habits on. Selection of products is not based on any valid criteria as eco certificates, it is simple selection of goods which have been marketed or visually designed to have connotation with being natural and green.

In 2016 series of articles "I commit to green" are introduced. The promise of the series is: "Ieva has committed to a new, beautiful and greener life. Whether it is doable and how comfortable, simple and cheap or expensive it is, we will discover step by step in the series of articles" (Ieva, 24.08.2016). It is important to stress that series of articles have been created with financial support from the Latvian Environmental Protection Fund. Thus this series are not entirely initiative of the magazine to educate its readers on issues of sustainability, but action from state. First article of this series is dedicated to electricity on how electricity is influencing environment and can harm it, why should society save electricity: "Energy saving is the foundation of the whole green lifestyle." Article features small section "A real green finds", which contains various house appliances which can help in energy saving: temperature controller, LED lightbulb, night lamp for children and desk light (Ieva, 
24.08.2016). This selection of items is based on worthy information, providing data about electricity saving qualities of each device.

Column "I commit to green" on June $20^{\text {th }}$ focuses on the waste we are leaving behind and how to minimize waste we produce, recycle and create compost (Ieva, 20.07.2016). Article features small section "A real green finds", which describes various hygiene products. The context why "A real green finds" feature hygiene products is not given, relaying on common notion that hygiene products need to be changed on regular basis and/ or has a short product life. Section features: menstrual cup, sanitary towels from fabric, as well as specific brand of tooth paste and toothbrush. Later two are described as eco-friendly providing a valid reasoning as well - Ecocert certificate and packaging from recycled products.

In the period chosen for analysis other articles from this series were not printed. Altogether this series of articles are informative and provide useful information on sustainable and green lifestyle. Information on products however is still lacking valid reasons for selecting products to become the part of green consumer shopping chart. These are several articles which stress necessity to recycle, save resources, reduce waste, etc. Unfortunately, the notion of sustainability is not considered in other articles. Exactly opposite, more often it celebrates consumption. Magazine uses different holidays as reasons to celebrate and thus to buy different consumer goods. The idea of DIY (dot it yourself) is promoted in articles due to financial reasons, not to avoid unnecessary consumption, but to save some money: "Why spend money on decorating if things at your household can be useful as materials for creating ornamental." (Ieva, 28.11.2018) In the analysed period, there is No discussion during Christmas time regarding amount of consumption or necessity to reduce consumption. In Western cultures, it is believed that Christmas is the peak of consumerism which is achieved by merging holiday symbols, spiritual values and commercial activities (Clarke, 2006). Thus discussion on sustainable consumption or means how to reduce consumerism would be welcomed.

\section{Motivation for being green}

In magazine publications reasons for buying green consumer products are mostly concern with individualistic motives of wellbeing and living in clean environment. For example, article "I am eating so as not to get sick" tackles the idea of green nutrition from position of good health. Article claims that: "It is scientifically proven that nutrition is one of cornerstones of good health" (Ieva, 11.10.2017). Other example is story about finding alternative to stain removers is positioned from perspective of individuals' environmental concerns: "I am trying to reduce amount of so called chemical cleaning products I am using on daily basis" (Ieva, 11.10.2017). Article "Green approach to dressing up the house" starts with a question: "Can house be cleaned without the use of single drop of household chemicals?" Reason for going green in house cleaning is allergies. The main focus of the article is not environmental concerns due to the harm aggressive cleaning agents might cause, but the wellbeing of the individual and family especially children (Ieva, 13.05.2015).

Consumer is not motivated by notion of green, sustainable and responsible consumption. Consumer can prefer some product over others based on their status as natural. Meaning that they are not artificial contains No artificial ingredients thus they are better for one's health and wellbeing. Concerns about environment are not the prime concern of consumer. Consumer is not buying his or her way into green identity because it isn't priority for him or her. Studies on attitudes toward environment protection show that people tend to consider themselves as environmental friendly. Unfortunately, their behaviour and consumptions habits prove that statement to be false. In study 
Household pro-environmental behaviour developments in Latvia: behavioural practice and values orientation $81 \%$ of respondents have indicated that protection of the environment is either very important ( $23 \%$ ) or rather important (58 \%) to them. Same study shows that their behaviour does not match the criteria of being environmentally friendly. Describing their food consumption patterns more than $1 / 3$ of respondents admit, they consume meat every day (37.7 \%) or at least $2-3$ times a week (48,8 \%). $59.5 \%$ do not recycle, only $15.3 \%$ have their dwelling totally insulated and only $32.9 \%$ drive cars that consume less than 6.5 litre of fuel per $100 \mathrm{~km}$. The most common proenvironmental behaviour is using reusable shopping bag. $48.7 \%$ of our respondents report using it always and $38 \%$ - using it sometimes (Brizga, Ikstens, et.all 2017).

\section{Conclusions, proposals, recommendations}

1) What in publications is meant by sustainability, green and natural and eco-friendly?

2) In the analysed period, there are few publications which tangle the issues of green lifestyle and green consumption. This is not top topic for magazine to write about, given the frame of publications - lifestyle magazine for women. Issues of green consumption however can be addressed as integral part of many various stories, but this strategy is not used in magazine.

3) What reasons if any are provided for positioning consumer goods and lifestyles as eco-friendly, natural and sustainable?

4) Magazine relies on information provided by marketing using terms like 'natural' without any restrains and valid evidence. Both products, ingredients and product qualities can be denoted as natural providing reader with No further information what it stands for. Term 'natural' is not used as argument which positions product as better or superior to other products. Products status as 'natural' is one of its qualities. Consumer is the one to make decision if 'natural' is reason enough to bay any certain product.

5) What is identity of green consumer?

6) In magazine publications, identity of green consumer is The Individual Green Citizen (Prothero, McDonagh, Dobscha 2010). Individual green citizen is consumer whose consumption acts are primarily based on micro motivations and focus on an individual's right to better environmental circumstances. Examples include the purchasing of organic products for individual health reasons or reducing waste because it is economically advantageous to do so. Identity of Individual Green Citizen is implicitly and explicitly present in various articles. It might be that being green is desirable social identity, but doing green is still behaviour to be learned. Buying green also is still practice to be acquired; media can be great tool in helping doing so. Unfortunately, in case of weekly lifestyle magazine Ieva buying green is something reader has to learn on his/ her own.

\section{Acknowledgements}

This work has been funded by Fundamental and Applied Research Projects program project "Latvia's Media Ecology: Analysis of Changes Caused by the Fourth Industrial Revolution."

\section{Bibliography}

1. Brizga, J., Feng, K., Hubacek, K. (2017). Household Carbon Footprints in the Baltic States: A global multiregional input-output analysis from 1995 to 2011. Applied Energy. Volume 189, pp. 780-788.

2. Buttel, F. (2003). Environmental Sociology and the Explanation of Environmental Reform. Organization \& Environment. 16(3), pp. 306-344.

3. Clarke, p. (2006). Christmas Gift Giving Involvement. Journal of Consumer Marketing, 23(5). pp. $283-291$.

4. Cohen, M. (2001). The Emergent Environmental Policy Discourse on Sustainable Consumption. In Cohen, M., Murphy, J. (eds) „Exploring Sustainable Consumption: Environmental Policy and the Social Sciences”. London: Pergamon. pp. 21-37. 
5. Giddens, A. (1991). Modernity and Self-identity. Cambridge: Polity Press.

6. Kantar TNS. Prese. Retrieved:http://www.kantartns.Iv/petijumu-dati/prese/ Access: 06.02.2019.

7. Ottman, J. (1993). Green marketing: Challenges \& opportunities for the new marketing age. Lincolnwood: NTC Business Books.

8. Prothero, A., Connoly, J. (2008). Green Consumption Life-politics, risk and contradictions. Journal of Consumer Culture. Volume 8(1), pp. 117-145.

9. Prothero, A., McDonagh, P., Dobscha, S. (2010). Is Green the New Black? Reflections on a Green Commodity Discourse. Journal of Macromarketing. Volume 30(2), pp. 147-159.

10. Ruppert-Stroescu, M. , LeHew, M., Hiller Connell, K. Armstrong, C. (2015). Creativity and Sustainable Fashion Apparel Consumption:The Fashion Detox.Clothing and Textiles Research Journal. Volume 33(3), pp. 167-182.

11.Sarkar, A.N. (2012). Green Branding and Eco-innovations for Evolving a Sustainable Green Marketing Strategy. Asia-Pacific Journal of Management Research and Innovation. Volume 8(1), pp. 39-58.

12. World Commission on Environment Development (1987). Our common future. Oxford: Oxford University Press.

\section{Magazines:}

1. Ieva. (12.03.2014). Atklajot zalo dzivesveidu. Ekologiski un veseligi, ka just, est un dzivot labak (Discovering green lifestyle. Ecological and healthy - to feel, eat and live better). p. 46.

2. Ieva. (19.03.2014). Atklajot zalo dzivesveidu. Ekologiski un veseligi, ka just, est un dzivot labak (Discovering green lifestyle. Ecological and healthy - to feel, eat and live better). p. 36.

3. Ieva. (14.04.2014). Atklajot zalo dzivesveidu. Ekologiski un veseligi, ka just, est un dzivot labak (Discovering green lifestyle. Ecological and healthy - to feel, eat and live better). p. 48.

4. Ieva (24.08.2016). Apnemos dzivot zalak (I commit to green). pp. 44-47.

5. Ieva, (20.07.2016). Apnemos dzivot zalak (I commit to green). pp. 40-43.

6. Ieva, (28.11.2018). Tava vainaga strategija (Your crown strategy). pp. 34-35.

7. Ieva, (27.10.2017). Es edu ta, lai neslimotu (I am eating so as not to get sick). pp. 44-45.

8. Ieva, (13.05.2015). Zala pieeja majas uzkopsanai (Green approach to dressing up the house). pp. 58-59. 